\title{
Risk assessment of the potential ecological and geochemical hazard of the functioning of mining complexes
}

\author{
Olga Krinochkina $^{1 *}$ \\ ${ }^{1}$ Moscow State University of Civil Engineering, Yaroslavskoye Shosse, 26, Moscow, 129337, Russia
}

\begin{abstract}
The aim of this work is to present a methodology for assessing the potential ecological and geochemical hazard of environmental pollution during the creation of new and functioning of existing mining complexes using the example of studying representative objects. The objects were selected according to the principle of the most saturated deposits, which serve as the core of mining complexes, toxic elements and the scale of mineralization, i.e. reserves of the deposits themselves. The methodology for assessing potential ecological and geochemical hazards is based on the following three principles: hierarchical approach; significance of the assessments; objectivity of information. The first involves the comparison of proportionate units, because the calculation of risk is carried out in points. The significance of the assessments was achieved by using those factors that can have a significant impact on the environment during the development of the deposit and determine the degree of sustainability of the natural environment when exploration territories. The objectivity of information was achieved by using the necessary and sufficient number of factors for assessing the risk of exploration and development of deposits and a significant amount of data obtained from the results of ecological and geochemical work with appropriate metrological support and laboratory analytical studies only in accredited centers. The methodology involves taking into account the totality of natural and technogenic environmental impact factors when developing solid mineral deposits, ranking them by importance and actually their integral assessment. As a result of the study of a large number of mining objects, according to our own and published data, by the method of expert assessments, the main factors of the influence of the developed deposits on the environment located in various natural conditions were established. Among these factors, 4 groups are distinguished: mineralogenic, landscape, hydrogeological and technogenic.
\end{abstract}

\section{Introduction}

The topic of research is due to the extremely large number of developed mineral deposits (DD) in our country, located in various natural conditions and, in connection with this, having a completely different impact on the environment (EN). The basis of the risk

\footnotetext{
*Corresponding author: vdovinaok@mail.ru
} 
assessment of the potential ecological and geochemical hazard (PEGH) of environmental pollution during the operation of mining complexes (MC) is based on the accounting of the totality of natural and technogenic factors in the development of deposits. Only thanks to this approach is it possible to predict the response of the natural environment to the technogenic transformation associated with the development and concentration of ores. That is why the choice of solutions in the design, construction of mining enterprises and their operation should be based on the principles of planned management of natural resources [1].

This point of view of the author was developed on the basis of the ideas of Russian scientists M.I. Agoshkov, B.N. Laskorin, N.V. Melnikov, V.V. Rzhevsky, E.M. Sergeev, A.V. Sidorenko, T.S. Khachaturov, S.S. Schwartz, M.E. Pevzner., V.P. Kostovetsky, E.F. Emlin, Yu.E. Sayet, N.S. Kasimov, E.P. Sorokin, V.S. Arzhanova, V.P. Elpatievsky, N.I. Plotnikov, A.A. Kartsev and others.

As far back as 1984, N. I. Plotnikov and A. A. Kartsev proposed dividing technogenic hydrogeological processes into three groups according to the degree and nature of their predictability. They stood out - quantitatively predicted - here are the processes of changing hydrodynamic conditions under the direct influence of technogenesis, for example, the depletion of aquifers, the development of depression funnels in them. The second group included approximately predicted processes, for example, the spread of various contaminants in the strata, and the third group included processes predicted only at a qualitative level. The last group includes complex processes of interaction between aquifers, etc.

Potential ecotoxicity issues were addressed by such well-known geologists-geochemists as Ivanov V.V., Goleva R.V. [2], their followers L.N. Belan et al. For example, L.N. Belan calculated indicators of potential ecotoxicity for the main pollutant elements of the Bashkir Trans-Urals tailing ponds [3].

The article discusses the potential hazard from chemical pollution of environmental components such as surface and groundwater, soil, bottom sediments. The immediate objects of study were natural-technogenic systems (NTS) within the developed deposits with their mining complex.

\section{Materials and methods}

Research methods included field observations, geochemical testing, multi-scale ecological and geochemical mapping, desk processing of materials. The laboratory complex included: inductively coupled plasma mass spectrometric analysis (ICP-MS) for ground and surface water samples and mobile forms of elements for soils and bottom sediments and atomic absorption method for gross forms of mercury in all samples.

Studies have been conducted at representative mining sites. They were chosen, as already mentioned, by their highest saturation with toxic elements and by the scale of mineralization. The pyritic deposits of the Southern Urals meet these criteria. In their composition, most of the ore elements are in the form of sulfides, which in the development of deposits inevitably turn into sulfates, increasing the rate of migration of heavy metals by several times [4].

Pyritic deposits, due to their genesis, are characterized by significant ore reserves. Among them were selected sulphide deposits of the Southern Urals. The ore-forming elements of these deposits are the toxic elements of $\mathrm{Zn}, \mathrm{Pb}$ and $\mathrm{Cu}$, and their pathfinder elements are highly toxic $\mathrm{Cd}, \mathrm{As}, \mathrm{Hg}$, etc.

Another group of representative sites is the apatite-nepheline deposits of the Khibiny Tundra: Kukisvumchorr, Yukspor, Apatitovy circus, Plateau Rasvumorr, located on the Kola Peninsula. This group of deposits is also characterized by very large ore reserves, a 
long mining period and a set of hazardous environmental pollutants, such as rare, rare earth and radioactive elements, as well as $\mathrm{Sr}, \mathrm{F}$, etc.

Another criterion for the selection of objects of study was various landscape conditions for their location.

The basics of PEGH risk assessment of developed deposits are:

- $\quad$ in the selection of factors for their assessment in mining, which play a substantially positive or negative role, in relation to chemical pollution;

- in assessing the degree of favorableness of the natural and technogenic conditions of the territories for their mining development;

- in the integrated assessment of PEGH designed for exploration and development the deposits.

\section{Results and discussion}

The choice of factors was carried out by expert assessment, based on available own and attracted information [5]. The most important natural risk assessment factors for developed deposits were recognized: mineralogical, landscape, and hydrogeological, and technogenic - the duration and methods of deposit development.

Among the mineralogical factors, only two of the most significant for the assessment of PEGH were chosen - the composition and reserves of ores. The values of the factors were differentiated on the basis of qualitative and quantitative indicators into 4 groups, each of which was assigned a specific point (from 1 to 4 ) for increasing the degree of their potential danger. So the minimum point (1) was assigned to the lowest value of the parameter, and the highest point (4) - to the maximum.

A relatively narrow range (from 1 to 4 ) of points was a condition for limiting the number of factors used, since it is quite obvious that with an increase in their number, the significance of each individual factor in the total assessment decreases, and with a sufficiently large number of them, the additive assessments are leveled [6]. Therefore, it was decided to limit the number of factors to 7 . With this approach, the weight of each of the factors in its group significantly affects the total assessment of the corresponding block and the integral assessment of the mining object as a whole.

The degree of environmental pollution during deposit development is directly dependent on its size, i.e. ore reserves. According to the gradation of reserves, deposits are subdivided according to the size category into small, medium, large (classification in accordance with the order of the Ministry of Natural Resources of Russia No. 50, 1997) and very large, or unique [7].

The composition of the ores, according to the author, is a determining factor in environmental pollution during field development, since it is he who dictates the acid-base environment, on which the level of pollution of all natural environments depends.

In addition, the ores themselves are often a concentrate of highly toxic elements. They can be subdivided into hazard classes, according to Order 536 of the MINISTRY OF NATURE, dated 04.12.2014, depending on the dominant elements in the ore composition. But the degree of danger of chemical pollution of the environment depends on how much toxic element is contained in the ores. And this is precisely what determines the reserves of the deposit. Therefore, according to the above indicators, deposits (dominant ore elements in the composition of ores and the size category of deposits) were divided by the author, according to the matrix table (Fig. 1), into: highly hazardous (4 points), hazardous (3 points), moderately hazardous ( 2 points) and low hazardous (1 point). 


\begin{tabular}{|c|c|c|c|c|}
\hline $\begin{array}{c}\text { category of } \\
\text { deposits }\end{array}$ & VI & III & II & I \\
\hline Highly large & & & & \\
\hline Large & & & & \\
\hline Medium & & & & \\
\hline Small & & & & \\
\hline
\end{tabular}

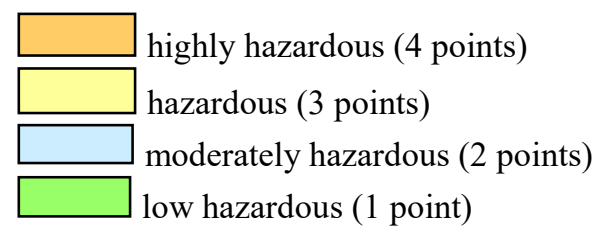

Fig. 1 Matrix for determining the potential ecological and geochemical hazard of mineral deposits [8].

So, when considering the prospects for the development of any deposit, one should study the composition of the ores (the percentage of recoverable metal is given in the passport of each deposit). Then, based on the percentage ratio, select the prevailing ore element, or elements. For example, the Uchaly deposit is large. $\mathrm{Cu}$ prevails in the composition of ore elements - this is an element of hazard class 3, but in the composition of the same ores there are $\mathrm{Pb}$ and $\mathrm{Zn}$ - elements of hazard class 1 . They add up to a larger percentage. This means that the total effect of the impact of these elements (hazard class 1) on the environment during deposit development will be greater and the Uchaly deposit should be classified as highly hazardous (4 points).

A group of landscape factors is considered on the example of objects of research located in different latitudinal zones, and, consequently, in sharply different natural conditions. As a result of the studies, landscape-forming factors were studied in the zones of MC influence, among which the most significant are types of climate, topography and soils.

The author has established a close relationship between the type of climate and its effect on the pollution of the hydrosphere. On the example of the Khibiny NTS, it is shown that due to the multiple dilution of natural waters with abundant precipitation, the salinity of groundwater and surface water does not exceed the standard values within the developer deposit and the entire zone of influence of Apatit MC. This is due to the humidity of the climate, which is typically humid here. Background natural waters at the deposit development site are ultra-fresh, less often - fresh. The low mineralization of natural waters is also facilitated by the low volatility within the NTS of the Khibiny Tundra deposits.

A completely different situation is observed at the Uchaly field, located on the eastern slope of the South Urals. The climate here is sharply continental with dry, hot summer, with prevalence of evaporation over precipitation, i.e. is typically arid, which leads to a delay in the water-soluble salts at the evaporation barriers during the dry season [9]. In winter, with a sharp temperature difference, so-called freezing occurs at the contact of ore dumps with basement waters, which contributes to the enrichment of these waters with toxic elements of ores. As a result, the entire hydrosphere of the NTS is polluted.

The polarity of the above phenomena is most clearly manifested in the distribution of the total mineralization of surface and groundwater objects. If the total mineralization for pyritic deposits of the Urals reaches $14 \mathrm{~g} / \mathrm{dm}^{3}$, then its maximum values for mineral deposits (MD) of the Khibiny Tundra, even in the area of sedimentation tanks of apatitenepheline factories (apatite-nepheline processing plant -1, 2, 3), do not exceed 0.7 $\mathrm{g} / \mathrm{dm}^{3}[10]$.

Thus, using the example of general mineralization, which is considered by the author as a generalized indicator of pollution of the hydrosphere and the environment, in general, it 
can be seen that the self-cleaning ability of mining areas with a humid climate is much higher than with arid and semi-arid ones, which include all territories of pyritic polymetallic deposits of the South Ural.

Thus, in the long-term planning of mineral deposit development, it is necessary to take into account the type of climate of the exploration territory. The risk of PEGH during deposit development increases from humid to arid and in humid climates it will be 1 point, semi-humid - 2 points, semi-arid - 3 points, and 4 in the arid one (Table) [8].

Important factors of landscape resistance to chemical pollution are soil and relief types. All landscape factors are closely interrelated, but the relationship between the genetic types of relief and soils is most important for PEGH assessing of developed deposit; it is they, ultimately, that determine the landscape's resistance to pollution. The team of authors [11] grouped soils according to their resistance to pollution, which is reflected in Fig. 2.

Table 1. Factors for assessing the potential ecological and geochemical hazard of chemical pollution of the prospective mining development territories

\begin{tabular}{|c|c|c|c|c|c|}
\hline \multirow{2}{*}{\multicolumn{2}{|c|}{ Assessment factors }} & \multicolumn{4}{|c|}{ Points } \\
\hline & & 1 & 2 & 3 & 4 \\
\hline \multicolumn{6}{|c|}{ Natural conditions } \\
\hline$\stackrel{\infty}{\Sigma}$ & $\begin{array}{c}\text { Hazard degree } \\
\text { of deposit }\end{array}$ & $\begin{array}{c}\text { Low } \\
\text { hazardous }\end{array}$ & $\begin{array}{c}\text { Moderately } \\
\text { hazardous }\end{array}$ & Hazardous & $\begin{array}{c}\text { Highly } \\
\text { hazardous }\end{array}$ \\
\hline \multirow{2}{*}{ 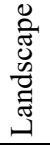 } & Climate Types & Humid & Semi-humid & Semi-arid & Arid \\
\hline & $\begin{array}{l}\text { Resistance of } \\
\text { landscapes }\end{array}$ & $\begin{array}{l}\text { Resistant (1 } \\
\text { point) }\end{array}$ & \multicolumn{2}{|c|}{ Medium resistant (2 points) } & $\begin{array}{c}\text { Low } \\
\text { resistant (3 } \\
\text { points) }\end{array}$ \\
\hline \multirow{2}{*}{ 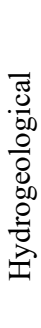 } & $\begin{array}{c}\text { Water } \\
\text { exchange } \\
\text { zones } \\
\text { according to } \\
\text { its degree } \\
\text { intensities } \\
\end{array}$ & $\begin{array}{c}\text { Active } \\
\text { water } \\
\text { exchange (1 } \\
\text { point) } \\
\text { (Cw from } \\
10 \text { to } 1) \\
\end{array}$ & \multicolumn{2}{|c|}{$\begin{array}{l}\text { Difficult water exchange ( } 2 \text { points) } \\
(\mathrm{Cw} \text { from } 1 \text { to } 0.1)\end{array}$} & $\begin{array}{c}\text { Stagnant } \\
\text { water } \\
\text { exchange } \\
(3 \text { points) } \\
\text { (Cw less } \\
0.1)\end{array}$ \\
\hline & $\begin{array}{l}\text { Aquifer } \\
\text { protection } \\
\text { degree }\end{array}$ & High & Medium & Low & Poor \\
\hline \multicolumn{6}{|c|}{ Technogenic conditions } \\
\hline \multirow{2}{*}{ 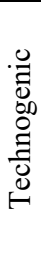 } & $\begin{array}{c}\text { Duration of } \\
\text { MD } \\
\text { development }\end{array}$ & $\begin{array}{c}\text { Less than } 5 \\
\text { years }\end{array}$ & $5-10$ years & $10-20$ years & $\begin{array}{l}\text { More than } 20 \\
\text { years }\end{array}$ \\
\hline & $\begin{array}{l}\text { Method for } \\
\text { MD } \\
\text { development }\end{array}$ & $\begin{array}{l}\text { Closed and } \\
\text { undergroun } \\
\mathrm{d} \text { leaching }\end{array}$ & Combined & Outdoor & Heap leaching \\
\hline
\end{tabular}

But, according to the author, these types of soils characterize only their ability to deposit pollution, and the resistance of landscapes is determined by the prevailing type of topography and soils together. This is confirmed by the data below.

Khibiny soils do not have sufficient buffering, because soils here, according to soil surveys, are primitive, low humus, illuvial, sometimes peat-boggy. The relief of the deposit territory is dissected. Significant areas are occupied by the midlands and lowlands. The steepness of the slopes within the Khibiny Mountains increases sharply from the foot (10$20^{\circ}$ ) to the peaks $\left(70-85^{\circ}\right)$, which plays a decisive role in the formation of the zoning of soil pollution. The relief in combination with the type of soil allows us to consider the landscape in the influence zone of developed deposit resistant to pollution. This is also confirmed by the distribution of the total pollution index (TPI), the values of which, in most 
of the mining area, range from 8 to 12 . And only within the accumulative terraces, in the lower flow of the river Belaya, in the area of tailing ponds of enrichment plants, there are insignificant areas (not more than $10 \%$ of the territory) with TPI from 16 to 32, with TPI of more than $32-3-4 \%$ of the territory. When combining the prevailing denudation relief and soil type, according to the matrix table and Figure 2, the territory of the developed deposit of the Khibiny Tundra is resistant to chemical pollution (1 point).

\begin{tabular}{|c|c|c|c|}
\hline Main types & \multicolumn{3}{|c|}{ Types and subtypes of soils* } \\
\cline { 2 - 4 } genetic types of relief & Resistant & Medium resistant & Low resistant \\
\hline Denudation & & & \\
\hline Downslope & & & \\
\hline Accumulative & & \\
\hline & & \\
\hline & & \\
\hline &
\end{tabular}

Fig. 2 Matrix for determining the landscape resistance (graduation: 1- resistant; 2 - medium resistant; 3 - low resistant; symbols of soil types and subtypes are given according to [12])

Let us further consider the relief in the zone of the Uchaly deposit. It belongs to the mid-mountain, because absolute elevation ranges from $450 \mathrm{~m}$ to $650 \mathrm{~m}$ (Fig. 3).

When comparing the maps of terrain relief and soil pollution by the total pollution index (TPI) - (Fig. 4) of the Uchaly natural and technogenic system, it can be seen that the zones of unsatisfactory ecological and geochemical state occupy the accumulative relief forms, and the cleanest ones are denudation ones. Since chernozems (leached and podzolized) prevail within the accumulative landforms on the South Ural developed deposits, soil pollution here is more intense than within the Khibiny Tundra deposits.

The values of the total pollution index here reach 32 or more. The landscape resistance to pollution for the area of the Uchaly deposit is estimated at 2 points.

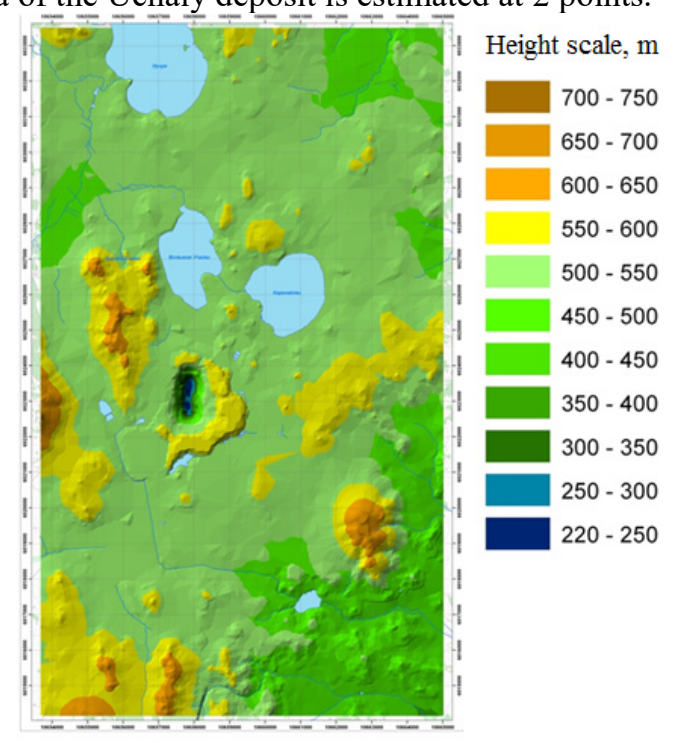

Fig. 3 Map of the ruggedness of the relief of the Uchaly NTS. Scale of heights relative to sea level, $m$

Thus, the landscape resistance to chemical pollution is determined by the prevailing genetic types of topography and soils, together. 
Among the hydrogeological factors in the deposit development, the intensity of groundwater exchange and the protection of groundwater are recognized as the most significant.

The rate of water exchange according to Kamensky G.N. is the coefficient of water exchange $(\mathrm{Cw})$, which is understood as the ratio of the annual discharge of groundwater to the total resources of the underground pool. This value ranges from 1 to 10 or more for groundwater and from 0.1 to 0.00001 for artesian waters. That is, within the artesian pools, complete water exchange can occur over millennia, which is comparable with geological time.

This corresponds to the understandings of Ignatovich N.K. about water exchange zones of the hydrogeological section. He identifies a zone of active, stagnant and difficult water exchange. Because when preparing the MD for development, as a rule, it is not enough to calculate the water exchange coefficient of hydrogeological parameters, an approximate assessment of the water exchange intensity by the degree of pollution of groundwater by introduced elements within the water exchange zones of the hydrogeological section is possible. The degree of water pollution is determined relative to the background. The gradations for calculating the degree of PEGH by the intensity of water exchange are as follows: from 1 to 10 for the zone of active water exchange, from 1 to 0.1 - stagnant, for zones of difficult water exchange, less than 0.1 .

In case of contamination during deposit development in the zone of active water exchange, where $\mathrm{Cw}$ ranges from 1 to 10 , $\mathrm{PEGH}$ will be assessed at 1 point, stagnant $(\mathrm{Cw}$ from 1 to 0.1 ) at 2 , and difficult (Cw less than 0.1 ), which is very unlikely - 3 points.

According to the ideas of K.E. Morau [13], which is shared by the author, the upper boundary of the zone of water exchange is the aeration zone, the lower is the part of the hydrogeological section, where discontinuous tectonics is already slightly manifested.

Consider the justification of the above parameter for the Uchaly copper-pyrite deposit. According to the stock materials, it is known that the zone of intense fracturing here reaches $1000-1100 \mathrm{~m}$. Groundwater pollution at the horizon level of $460 \mathrm{~m}$ according to 2014 data is insignificant. The excess relative to the background is noted only for individual components $\left(\mathrm{Fe}^{2+}, \mathrm{Fe}^{3+}, \mathrm{Cu}^{2+}, \mathrm{Zn}^{2+}, \mathrm{Pb}^{2+}, \mathrm{Al}^{3+}, \mathrm{SO}_{4}{ }^{2-}\right)$. That is, groundwater pollution affects only the area of active water exchange (Cw 1-10) - 1 point.

The protection of groundwater also refers to hydrogeological factors and is assessed by the presence or absence of confining in the roof of an aquifer. If a water-resistant horizon exists and has a consistent capacity, then the degree of protection is high and is estimated at 1 point. If there is a small amount of erosion windows, the protection is average and is estimated at 2 points. If the horizon is not sustained along strike and thickness, there are numerous erosion windows within it, its security is low - 3 points. In the absence of a water-resistant horizon, or its local development, the degree of protection is unsatisfactory 4 points.

So, for the water supply of the city of Uchaly, the Middle Devonian Karamiltash aquifer is used. The shielding waterproof horizon cannot be called sustained in power and strike, because fragmentally, the Karamiltash horizon reaches the day surface in the form of springs. Its composition revealed excesses of maximum permissible concentration (hereinafter, for the normalization, the values of chemicals in the water of water bodies of drinking and cultural and domestic water use according to GN 2.1.5.1315-03 are taken) for cadmium, magnesium, aluminum, zinc, lead, iron, calcium, selenium, beryllium, copper, magnesium, arsenic and molybdenum. Mineralized waters (5.0-10.0 g/l) were determined at several points. 


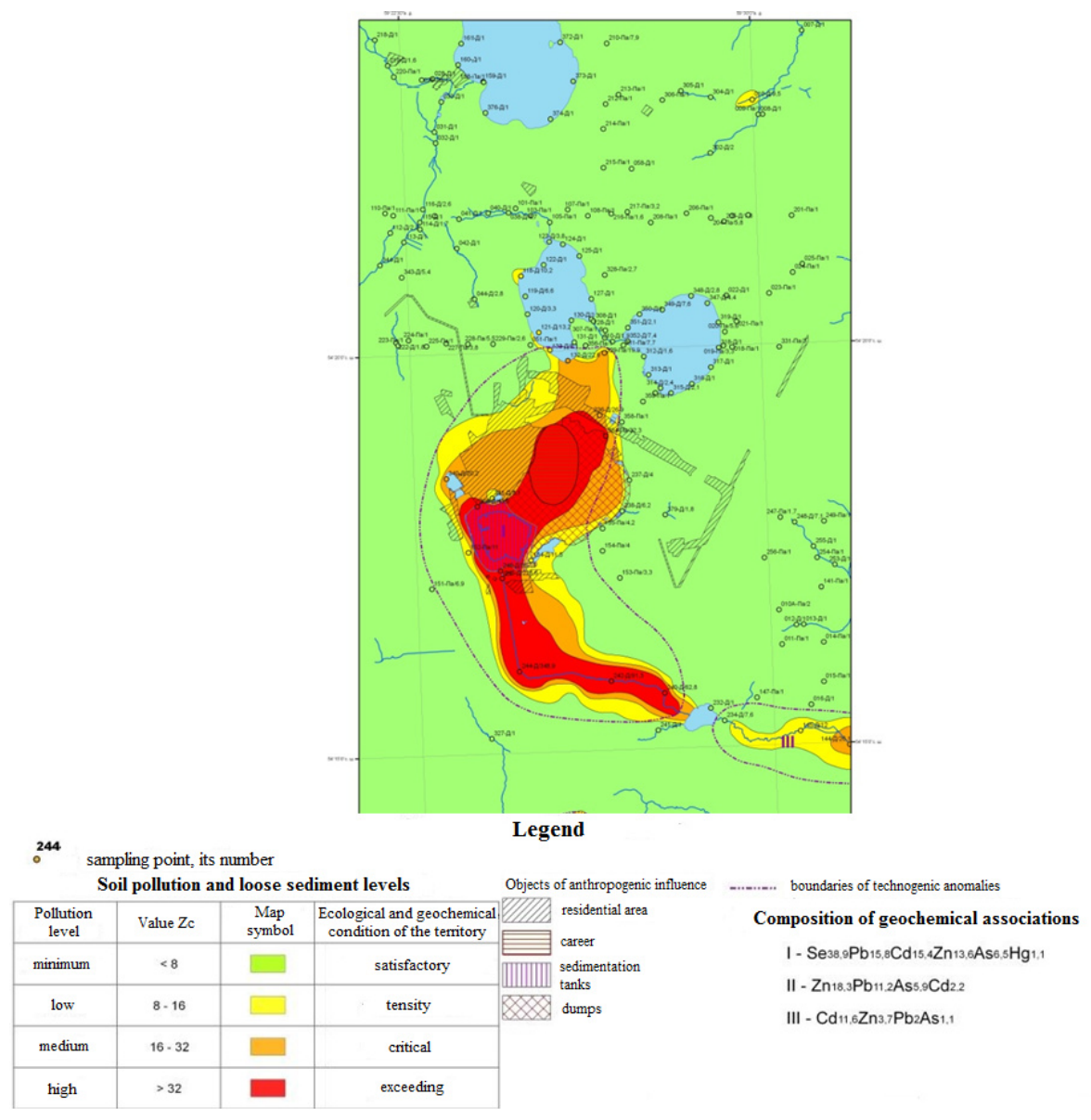

Fig. 4 Map of soil pollution of the Uchaly NTS by TPI [8]

Thus, according to the protection degree of groundwater PEGH of the Uchaly deposit is 3 points.

Technogenic factors of influence during the development of deposit development on the state of the environment, as a rule, exacerbate the natural enrichment of it with various elements, or chemical compounds [14]. But technogenic risk factors, being manageable, can be adjusted depending on the natural conditions of field localization [15]. To minimize their influence, optimization of the choice of technical conditions for mining of territories is proposed. The most significant of these are the duration and method of deposit development. They are selected depending on the degree of vulnerability of the natural environment of the development territory. Therefore, proceeding to the integrated assessment of PEGH developed deposits, it is necessary to first evaluate the degree of vulnerability of the developed deposits, which is determined by the effect of the total influence of natural factors.

So, the more vulnerable the natural environment, the more extended should be the duration of the development of the deposit. If the natural conditions of the deposit are such that an intensive development route can lead to an extremely dangerous condition of the NTS (PEGH is very high), then the duration of its development should be inversely proportional to the total assessment of the natural factors of PEGH. PEGH gradations in terms of deposit development duration are as follows: less than 5 years - 1 point, 5-10 years - 2 points, 10-20 years -3 points, more than 20 years -4 points. 
A similar approach should be applied when choosing methods for developing deposits. The most sparing is considered to be the closed method (the underground leaching method also applies) of ore mining (1 point), followed by the degree of increase in influence on the environment - combined ( 2 points), open ( 3 points) and heap leaching ( 4 points).

The integral assessment of PEGH is calculated as the sum of single estimates for groups of mineralogical, landscape, hydrogeological and technogenic factors. Its gradations are defined as low (7 points), medium (from 8 to 14), high (from 15 to 19) and very high (more than 19).

\section{Conclusions}

1. The proposed approach to risk assessment of ecological and geochemical hazards from the activities of mining enterprises allows to plan its construction taking into account the natural conditions of localization of deposits, the main of which are genetic types of relief and soils, hydrogeological and mineralogical.

2. It was established by the example of two diametrically opposite naturaltechnogenic systems of the Uchaly developed deposits and deposits of the Khibiny Tundra that are diametrically opposed in landscape-geochemical conditions, that the resistance of landscapes to chemical pollution determines the combined influence of the prevailing genetic types of relief and soils.

3. In the long-term planning of the development of MD, it is necessary to take into account the type of climate of the development territory. The risk of PEGH in the development of deposits increases from humid to arid, which was established by the example of the influence of total mineralization on the state of NTS developed deposits.

4. The dominant hydrogeological factors in assessment of the ecological and geochemical risk of pollution of NTS, as established by the example of the abovedescribed developed deposits, are the intensity of groundwater exchange and their protection.

5. Among the mineralogical factors for assessment of the ecological and geochemical risk of contamination of the NTS developed deposits, two of the most significant ones were identified - ore composition and reserves.

6. Technogenic, and therefore controlled ecological and geochemical risk factors, are the duration and method of deposit development. Thanks to this approach, the optimal selection of technical conditions for environmentally friendly mining of territories is possible.

The methodology considered allows to assess the risk of ecological and geochemical hazards of both newly designed mining complexes and those already functioning.

\section{References}

1. O.K. Krinochkina, Collection of materials of the International Scientific Conference in the framework of the Year of Ecology of the Russian Federation. Department of Engineering Surveys and Geoecology (NRU MGSU), 25-26 (2018)

2. R.V. Goleva, V.V. Ivanov, I.I. Kupriyanova et al, Environmental assessment of potential ecotoxicity of ore deposits. Guidelines (2001)

3. L.N. Belan, Herald of the OSU 6, 113-117 (2005).

4. L.N. Belan, Geoecology of the mining regions of Bashkortostan. Ufa: Bash.GU (2003)

5. O.K. Krinochkina, Exploration and Protection of Subsurface Resources 4, 54-60 (2018) 
6. O.K. Vdovina, Bulletin of the Moscow Society of Naturalists. Geological Department 3, 68-72 (2008)

7. L.A. Krinochkin, A.A. Golovin, N.G. Gulyaeva, N.Ya. Trefilova, Exploration and protection of mineral resources 11, 8-15 (2004)

8. Geological atlas of Russia. ed. Smyslov A.A., VSEGEI, SPb (1996)

9. O.K. Krinochkina, Subsoil Use XXI Century 6, 134-143 (2017)

10. E.F. Emlin, Technogenesis of pyritic deposits of the Urals. Sverdlovsk: Publishing House of the Ural State University (USU) (1991)

11. O.K. Krinochkina, A.A. Lavrusevich, Sergeevsky readings. Geoecological safety of the development of mineral deposits. Materials of the annual session of the Scientific Council of the Russian Academy of Sciences on the problems of geoecology, engineering geology and hydrogeology as part of the Year of Ecology in Russia. Scientific Council of the Russian Academy of Sciences on the problems of geoecology, engineering geology and hydrogeology, 384-389 (2017)

12. E.P. Sorokina, E.M. Nikiforova et al, Landscape ecological-geochemical map of Russia on a scale of 1:5,000,000 with an explanatory note (1995)

13. E.M. Ivanov, The classification of soils of the USSR. Nauka, Moscow (1976)

14. K.E Morau., E.N. Matveeva, Bulletin of the Institute of Geophysics and Geology, Academy of Sciences of Moldova 2, 108-122 (2011)

15. O.K. Krinochkina, Sat Proceedings of the II Potapov Readings, Interuniversity Conferenc, NRU MGSU, 96-98 (2016)

16. O.K. Vdovina, Geoinformatics 4, 45-52 (2008) 